\title{
Has U.S. Monetary Policy Tracked the Efficient Interest Rate?
}

\author{
Vasco Cúrdia ${ }^{\mathrm{a}}$, Andrea Ferrero ${ }^{\mathrm{b}}$, Ging Cee $\mathrm{Ng}^{\mathrm{c}}$, Andrea Tambalottid ${ }^{\mathrm{d}, *}$ \\ ${ }^{a}$ Federal Reserve Bank of San Francisco \\ ${ }^{b}$ University of Oxford \\ ${ }^{c}$ University of Chicago \\ ${ }^{d}$ Federal Reserve Bank of New York
}

\begin{abstract}
Interest rate decisions by central banks are universally discussed in terms of Taylor rules, which describe policy rates as responding to inflation and some measure of the output gap. We show that an alternative specification of monetary policy, in which the interest rate tracks the Wicksellian efficient rate of return as the primary indicator of real activity, fits the U.S. data better than otherwise identical Taylor rules. This result holds for a variety of specifications of the other ingredients of the policy rule, including the output gap, and of private agents' behavior.
\end{abstract}

Keywords: U.S. monetary policy, Interest rate rules, DSGE models, Bayesian model comparison JEL Classification: E43, E58, C11

We thank Ricardo Reis, Robert King (the editors) and an anonymous referee for their extremely valuable suggestions on how to sharpen the focus of the paper, and Alejandro Justiniano, Thomas Lubik, Ed Nelson, Giorgio Primiceri, Keith Sill, Chris Sims, and several seminar and conference participants for their comments. Matthew Hom provided excellent research assistance. The views expressed in this paper are those of the authors and do not necessarily reflect the position of the Federal Reserve Banks of New York or San Francisco, or the Federal Reserve System.

*Corresponding Author: Federal Reserve Bank of New York, 33 Liberty Street, 3rd Floor, New York, NY 10045. Phone: (212) 720-5657; Fax: (212) 720-1844

Email address: andrea.tambalotti@ny.frb.org (Andrea Tambalotti)

${ }^{1}$ We do not call these rules Wicksellian because Woodford (2003) and Giannoni (2014) already use this term to refer to interest rate rules that respond to the price level, rather than to inflation.

${ }^{2}$ Neiss and Nelson (2003) is an early attempt to evaluate the properties of the efficient real rate in a calibrated DSGE model. Trehan and $\mathrm{Wu}$ (2007) discuss the biases in the reduced-form estimation of policy rules with a constant intercept, when in fact the central bank responds to a time-varying equilibrium real rate, but they do not estimate this response. 
in the empirical literature, the idea that a neutral, or "equilibrium," interest rate might represent a useful reference point for monetary policy was familiar to Federal Reserve policymakers well before Woodford (2003) revitalized its Wicksellian roots. ${ }^{3}$ For example, in his Humphrey Hawkins testimony to Congress in May 1993, Federal Reserve Chairman Alan Greenspan stated that

“...In assessing real rates, the central issue is their relationship to an equilibrium interest rate, specifically, the real rate level that, if maintained, would keep the economy at its production potential over time. Rates persisting above that level, history tells us, tend to be associated with slack, disinflation, and economic stagnation - below that level with eventual resource bottlenecks and rising inflation, which ultimately engenders economic contraction. Maintaining the real rate around its equilibrium level should have a stabilizing effect on the economy, directing production toward its long-term potential." 4

Evaluating to what extent this type of reasoning had a measurable impact on the observed evolution of policy rates in the U.S. requires a structural model, since the equilibrium real rate is a counterfactual object. We compute this counterfactual in two variants of the standard New Keynesian DSGE model with monopolistic competition and sticky prices, estimated on data for the Federal Funds rate (FFR), inflation and GDP growth, as in the empirical literature on Taylor rules. Within this framework, we define production potential as the efficient level of aggregate output $y_{t}^{e}$, as in Justiniano et al. (2013) for instance, so that the equilibrium real rate that "would keep the economy at its production potential" is the efficient rate of return $r_{t}^{e}$. This interest rate is efficient because it is the one that would prevail if markets were perfectly competitive, rather than distorted by monopoly power and price dispersion.

Our exploration of the fit of $\mathrm{W}$ rules starts from a very simple specification, in which the FFR closes the gap with $r_{t}^{e}$ over time, and responds to inflation, as in

$$
i_{t}=\rho i_{t-1}+(1-\rho)\left(r_{t}^{e}+\phi_{\pi} \pi_{t}\right)+\varepsilon_{t}^{i} .
$$

The empirical performance of this baseline $\mathrm{W}$ rule is then compared to that of a more traditional $\mathrm{T}$ rule, based on Taylor (1993), in which economic slack is measured by the output gap. Under the T specification, the model's ability to fit the data deteriorates significantly. This surprising finding is robust to several variations in the ingredients of the policy rule, including the measurement of the output gap and the presence of a time-varying inflation target, as well as to the specification of the rest of the DSGE model.

Methodologically, the analysis follows a full-information, Bayesian empirical strategy. Each of the policy rules is coupled with the private sector's tastes and technology, resulting in a set of econometric models, one for each policy specification. These models are then estimated, so that their fit can be compared using marginal data densities. This criterion measures each model's overall ability to fit the data, rather than that of the policy equation alone, relative to a reference model, which in our case is the one associated with the $\mathrm{W}$ rule. This is the only formal approach to evaluating fit in the general equilibrium context needed to compute the counterfactual efficient real rate. However, our main findings based on marginal data densities are also corroborated by some more informal indicators of how well different policy rules account for the evolution of the FFR, and of the extent to which the resulting model is more or less sensible.

Aside from pointing to $\mathrm{W}$ rules as a promising tool to describe interest rate setting in practice, our results also suggest that this often neglected component of structural models can have a significant impact on their fit. The gap in marginal likelihoods between the best and worst fitting rules considered in this study can be as high as fifty log-points. As a reference, these differences in fit are of a similar order of magnitude as those between structural models estimated with or without stochastic volatility (e.g., Cúrdia et al., 2014).

\footnotetext{
${ }^{3}$ King and Wolman (1999) first showed that, in a New Keynesian model, it is optimal for the interest rate to track its efficient counterpart.

${ }^{4}$ Quantitative measures of this equilibrium interest rate are a regular input in the monetary policy debate at the Federal Reserve. A chart with a range of estimates of this rate is included in most published Bluebooks at least since May 2001. According to McCallum and Nelson (2011), this construct emerged in the early 1990s at the Federal Reserve as a gauge of the monetary policy stance following a shift of emphasis away from monetary aggregates, due to the difficulty of estimating a non-inflationary growth rate of money in the midst of financial innovation. See also Amato (2005).
} 
This evidence therefore underscores the importance for DSGE researchers of paying close attention to the specification of monetary policy.

The rest of the paper proceeds as follows. Section 2 presents our baseline model of private sector behavior, defines its efficient equilibrium and the associated levels of output and of the real interest rate, and introduces the baseline $\mathrm{W}$ and $\mathrm{T}$ rules. Section 3 discusses the methodology for the estimation and comparison of the models. Section 4 presents results for the baseline policy rules, making the case for the empirical superiority of the $\mathrm{W}$ rule. Section 5 explores the robustness of this conclusion to alternative specifications of the policy rules, and of the private sector's tastes and technology. Section 6 concludes. The online appendix contains a larger set of robustness results, along with a more detailed description of the baseline model and other supporting material.

\section{A Simple Model of the Monetary Transmission Mechanism}

This section outlines the log-linear approximation of the simple New-Keynesian model we bring to the data. The model describes the behavior of households and firms, with an interest rate feedback rule capturing the response of monetary policy to economic developments. Different specifications of this reaction function, coupled with the same tastes and technology for the private sector, give rise to different empirical models. Details on the microfoundations are in the online appendix.

An intertemporal Euler equation and a Phillips curve summarize the behavior of the private sector. Optimal consumption and saving decisions produce the Euler equation

$$
\tilde{x}_{t}=E_{t} \tilde{x}_{t+1}-\varphi_{\gamma}^{-1}\left(i_{t}-E_{t} \pi_{t+1}-r_{t}^{e}\right),
$$

which states that current real activity, measured by the variable $\tilde{x}_{t} \equiv\left(x_{t}^{e}-\eta_{\gamma} x_{t-1}^{e}\right)-\beta \eta_{\gamma} E_{t}\left(x_{t+1}^{e}-\eta_{\gamma} x_{t}^{e}\right)$, depends on future expected real activity and on the gap between the ex-ante real interest rate, $i_{t}-E_{t} \pi_{t+1}$, and its efficient level $r_{t}^{e}$. Here, $i_{t}$ is the nominal interest rate, $\pi_{t}$ is inflation, and $x_{t}^{e} \equiv y_{t}-y_{t}^{e}$ is the efficient output gap, i.e. the log-deviation of output, $y_{t}$ from its efficient level $y_{t}^{e}$.

The optimal pricing decisions of firms produce the Phillips curve

$$
\tilde{\pi}_{t}=\xi\left(\omega x_{t}^{e}+\varphi_{\gamma} \tilde{x}_{t}\right)+\beta E_{t} \tilde{\pi}_{t+1}+u_{t},
$$

relating a measure of current inflation, $\tilde{\pi}_{t} \equiv \pi_{t}-\zeta \pi_{t-1}$, to expected future inflation, real activity and an AR(1) cost-push shock $u_{t}$, generated by exogenous fluctuations in desired markups.

These two equations augment the purely forward-looking textbook version of the New Keynesian model with two sources of inertia, which improve its ability to fit the data. On the demand side, utility features internal habits in consumption, parametrized by $\eta_{\gamma}$. On the supply side, the prices that are not re-optimized in each period increase automatically with past inflation, by a proportion $\zeta$.

This model of private sector behavior is more stylized than in the workhorse empirical DSGE framework of Christiano et al. (2005) and Smets and Wouters (2007). In particular, it abstracts from capital accumulation and the attending frictions (endogenous utilization and investment adjustment costs) and from non-competitive features in the labor market (monopolistic competition and sticky wages). Nevertheless, it provides a reasonable description of the data on GDP, inflation and the interest rate - the series that are typically considered in the estimation of interest rate rules. Another advantage of working with a strippeddown baseline specification is that it made it possible to explore the robustness of the paper's main finding across a very large number of interest rate rules, without having to worry about computational constraints. Nevertheless, section 5.3 shows that $\mathrm{W}$ rules also outperform $\mathrm{T}$ rules in a medium-scale model.

\subsection{Output and the Real Interest Rate in the Efficient Equilibrium}

Efficient output, denoted by $y_{t}^{e}$, and the efficient real interest rate, denoted by $r_{t}^{e}$, are central constructs in our analysis. They represent the levels of output and of the real interest rate that would be observed in a counterfactual economy in which (i) prices are - and have always been - flexible, and (ii) desired markups are zero. In our framework, these assumptions result in a perfectly competitive economy, which would 
therefore deliver the efficient allocation. ${ }^{5}$ The corresponding equilibrium represents a "parallel universe," which evolves independently from the outcomes observed in the actual economy (Neiss and Nelson, 2003).

In this parallel universe, efficient output, expressed in deviation from the balanced growth path, evolves according to

$$
\omega y_{t}^{e}+\varphi_{\gamma}\left(y_{t}^{e}-\eta_{\gamma} y_{t-1}^{e}\right)-\beta \varphi_{\gamma} \eta_{\gamma}\left(E_{t} y_{t+1}^{e}-\eta_{\gamma} y_{t}^{e}\right)=\varphi_{\gamma} \eta_{\gamma}\left(\beta E_{t} \gamma_{t+1}-\gamma_{t}\right)+\frac{\beta \eta_{\gamma}}{1-\beta \eta_{\gamma}} E_{t} \delta_{t+1} .
$$

This equation implies that $y_{t}^{e}$ is a linear combination of past, current, and future expected values of productivity growth $\gamma_{t}$ and of the intertemporal taste shock $\delta_{t}$. These exogenous disturbances both follow $\operatorname{AR}(1)$ processes.

Given $y_{t}^{e}$, the intertemporal Euler equation implies

$$
r_{t}^{e}=E_{t} \gamma_{t+1}+E_{t} \delta_{t+1}-\omega E_{t} \Delta y_{t+1}^{e},
$$

from which we observe that the efficient real rate depends positively on the forecastable components of next period's productivity growth and preference shock, and negatively on those of the growth rate of efficient output, $\Delta y_{t+1}^{e}$. Intuitively, an increase in households' desire to consume early, which is captured by a persistent rise in $\delta_{t}$, puts upward pressure on the efficient real rate, so as to dissuade consumers from acting on their desire to anticipate consumption. Similarly, higher expected productivity growth requires steeper consumption profiles, and hence a higher real rate. Finally, the last term captures the negative effect on the interest rate of a higher expected growth rate of marginal utility, which in the efficient equilibrium is connected with the growth rate of hours, and hence of output.

These last two expressions highlight the close connection between the efficient levels of output and of the real rate, while Euler equation (2) ties together their respective gaps. According to (2), an interest rate gap maintained at zero forever closes the output gap, and vice versa. This observation suggests that $r_{t}^{e}$ can be a useful target for monetary policy in alternative to the efficient level of output, as an indicator of the economy's potential. In the context of policy rules, this alternative approach to assessing the amount of slack in the economy can be captured by an interest rate that tracks its efficient counter part, as in the $\mathrm{W}$ rules presented below.

\subsection{Monetary Policy: Baseline $W$ and T Rules}

To set up the comparison between policy rules that track the efficient real rate, or $\mathrm{W}$ rules, and those that react to the output gap instead, or $\mathrm{T}$ rules, we begin our analysis with two particularly simple specifications.

In the baseline $\mathrm{W}$ rule, the policy rate responds to the efficient real rate and to inflation, with some inertia, as in

$$
i_{t}=\rho i_{t-1}+(1-\rho)\left(r_{t}^{e}+\phi_{\pi} \pi_{t}\right)+\varepsilon_{t}^{i} .
$$

The coefficient on $r_{t}^{e}$ is restricted to one because this indicator represents a target for the actual interest rate. When the efficient rate rises, say because of an increase in households' desire to consume today, the actual rate follows, so as to close the interest rate gap, and hence keep output close to its efficient level.

In the baseline $\mathrm{T}$ rule, the central bank sets the nominal interest rate in response to inflation and the efficient output gap

$$
i_{t}=\rho i_{t-1}+(1-\rho)\left(\phi_{\pi} \pi_{t}+\phi_{x} x_{t}^{e}\right)+\varepsilon_{t}^{i} .
$$

In this case, demand pressures are captured by the deviation of output from its efficient level, to which the central bank reacts by increasing the policy rate.

Therefore, both baseline rules capture the typical reaction of monetary policy to real economic developments. In the $\mathrm{W}$ rule, these developments are summarized by the efficient real rate. In the T rule, they are captured by the output gap.

\footnotetext{
${ }^{5}$ The equilibrium in which prices are flexible, but desired markups fluctuate, is usually referred to as "natural" (Woodford, 2003). Barsky et al. (2014) discuss the relationship between natural and efficient equilibria in New Keynesian models and the neutral rate of interest in Wicksell (1898). Justiniano et al. (2013) connect these concepts to optimal policy.
} 
To bridge the gap between the empirical literature on interest rate rules and this paper's DSGE framework, equation (7) defines the output gap as the deviation of output from its efficient level. This choice, which might be controversial, is dictated by two considerations. First, it is internally consistent, since in our model $x_{t}^{e}$ is both the fundamental driver of inflation and the measure of slack that is relevant for welfare (e.g. Woodford, 2003). Second, the efficient output gap is a direct counterpart to the efficient real interest rate that measures economic activity in the baseline $\mathrm{W}$ rule.

The main drawback of this modeling choice is that computing $x_{t}^{e}$ requires a fully-specified model, while most of the measures featured in the empirical literature do not. For this reason, we later extend the comparison between $\mathrm{W}$ and $\mathrm{T}$ rules to specifications that include other definitions of the output gap, such as ones based on the HP and other statistical filters.

The presence of cost-push shocks in the model creates a trade-off between output gap and inflation stabilization. As a result, a $\mathrm{W}$ rule that simply set the real interest rate equal to its efficient level every period, hence maintaining a zero output gap, would be suboptimal. This is why $\mathrm{W}$ rules also respond to inflation, like T rules do. Moreover, a strong enough response of the nominal interest rate to inflation ensures determinacy of the rational expectations equilibrium.

\section{Inference}

We estimate the two alternative models associated with the $\mathrm{W}$ and $\mathrm{T}$ rules laid out in the previous section - and the many variants discussed below-with Bayesian methods, as surveyed for example by An and Schorfheide (2007). Bayesian estimation combines prior information on the model's parameters with its likelihood function to form a posterior density, from which we draw using Markov Chain Monte Carlo (MCMC) methods. We construct the likelihood using the Kalman filter based on the state-space representation of the rational expectations solution of each model under consideration, setting to zero the prior probability of the configurations of parameters that imply indeterminacy.

The observation equations are

$$
\begin{aligned}
\Delta \log G D P_{t} & =\gamma+y_{t}-y_{t-1}+\gamma_{t} \\
\Delta \log P C E_{t} & =\pi^{*}+\pi_{t} \\
F F R_{t} & =r+\pi^{*}+i_{t}
\end{aligned}
$$

where $G D P_{t}$ is real GDP, $P C E_{t}$ is the core PCE deflator (ex-food and energy), and $F F R_{t}$ is the average effective Federal Funds Rate (henceforth FFR), all sampled at a quarterly frequency. The constants in these equations represent the average growth rate of productivity $(\gamma)$, the long run inflation target $\left(\pi^{*}\right)$, and the average real interest rate $(r)$. The sample period runs from 1987:Q3 to 2009:Q3, although the main results are not affected by truncating the sample either at 2008:Q4, when the FFR first hit the zero bound, or at 2006:Q4, before the eruption of the recent financial crisis. We start the sample on the date in which Alan Greenspan became chairman of the Federal Reserve because this period is characterized by a reasonably homogenous approach to monetary policy, which is well-approximated by a stable interest rate rule.

Table 1 reports our choice of priors, which are shared across all the models we estimate. On the demand side, we calibrate the discount factor as $\beta=0.99$. This parameter, together with the balanced growth rate $\gamma$, and the habit coefficient $\eta$, determines the slope of the Euler equation $(2), \varphi_{\gamma}^{-1} \equiv\left(1-\eta_{\gamma}\right)\left(1-\beta \eta_{\gamma}\right)$, with $\eta_{\gamma} \equiv \eta e^{-\gamma}$.

\section{[Locate Table 1 about here.]}

On the supply side, the slope of the Phillips curve is also a function of deep parameters, $\xi=(1-\alpha)(1-\alpha \beta) /[\alpha(1+\omega \theta)]$, where $\alpha$ is the fraction of firms that do not change their price in any given period, $\theta$ is the elasticity of demand faced by each monopolistic producer and $\omega$ is the inverse Frisch elasticity of labor supply. Given our observables, only the slope $\xi$ can be identified. Its prior, centered around 0.1 , is somewhat higher than typical estimates of the New Keynesian Phillips curve (e.g. Galí and Gertler, 2007; Sbordone, 2002), but 
consistent with the low degree of price stickiness found in microeconomic studies such as Bils and Klenow (2004), given reasonable values for $\omega$ and $\theta .^{6}$

In the interest rate rules, the prior on the smoothing parameter $\rho$ has a dispersion wide enough to encompass most existing estimates. The priors for the feedback coefficients on inflation $\phi_{\pi}$ and real activity $\phi_{x}$ are centered around the original Taylor (1993) values of 1.5 and 0.5 , respectively.

To evaluate the fit of different policy rules, we compare the marginal data densities (or posterior probabilities) of the corresponding models. All these models share equations (2) and (3), but each is closed with a different interest rate rule. We estimate each model separately with the same data and priors, and compute its posterior probability using the modified harmonic mean estimator proposed by Geweke (1999). To compare fit across models, we calculate KR ratios, defined as two times the log of the Bayes factor. ${ }^{7}$

\section{Results: Wicksell or Taylor?}

Table 2 reports the posterior estimates of the parameters under the two baseline policy specifications, together with the models' marginal likelihoods and the implied KR criterion. The table conveys the excellent empirical performance of the $\mathrm{W}$ rule along three dimensions. First, the nearly eleven point difference in logmarginal likelihoods between the two models translates into a KR ratio above 20, which represents very strong evidence in favor of the model featuring the $\mathrm{W}$ rule.

[Locate Table 2 about here.]

Second, the posterior estimates of the parameters provide some insight into the empirical difficulties of the baseline T specification. For instance, the posterior of the slope of the Phillips curve $\xi$ is concentrated near extremely low values under this specification, with a median of 0.0021 . This value is two orders of magnitude smaller than the prior mean and at the extreme lower end of the available estimates in the DSGE literature (see, for example, the survey by Schorfheide, 2008).

A slope this low implies no discernible trade-off between inflation and real activity, so that inflation is close to an exogenous process driven by movements in desired markups. As a consequence, inflation indexation and persistent markup shocks become hard to distinguish as drivers of the observed inflation persistence. This lack of identification is reflected in bimodal posterior distributions of the parameters $\zeta$ and $\rho_{u}$, which are generated by MCMC draws with high $\zeta$ and low $\rho_{u}$, or vice versa, as shown in the online appendix. This feature of the posterior does not reflect intrinsic uncertainty on the source of inflation persistence in the model. It is due instead to the implausible estimate of the inflation process implied by the $\mathrm{T}$ specification, in which economic slack plays almost no role. In fact, the posterior of these two parameters is no longer bimodal in the $\mathrm{W}$ specification, which features a higher estimate of the Phillips curve slope and hence a tighter connection between inflation and marginal cost. This tighter connection also helps to identify the autocorrelation of markup shocks as the source of inflation persistence, with little role for inflation indexation, resulting in a more conventional and plausible description of the inflation process than in the $\mathrm{T}$ specification.

Finally, the interest rate rule coefficients imply a fairly strong reaction of policy to the output gap, but an extremely weak reaction to inflation, with a substantial fraction of the posterior draws for $\phi_{\pi}$ below one. These values are at odds with the large empirical literature that has found a forceful reaction to inflation to be one of the hallmarks of U.S. monetary policy since the mid-eighties. ${ }^{8}$ None of these problems appears in the model with the $\mathrm{W}$ rule, from which we conclude that this specification provides an overall more sensible description of the data.

The two indicators of the empirical plausibility of the W rule considered so far speak to the overall model's ability to account for the evolution of the entire vector of observables, rather than pointing to the success of

\footnotetext{
${ }^{6}$ For example, with $\omega=1$ and $\theta=8$, which corresponds to a desired markup of $14 \%, \xi=0.1$ implies $\alpha=0.4$, or an expected duration of prices of about five months.

${ }^{7}$ Kass and Raftery (1995) suggest that values of KR above 10 can be considered "very strong" evidence in favor of a model. Values between 6 and 10 represent "strong" evidence, between 2 and 6 "positive" evidence, while values below 2 are "not worth more than a bare mention."

${ }^{8}$ Values of $\phi_{\pi}$ lower than one do not necessarily generate indeterminacy, if accompanied by high values of $\phi_{x}$. Equilibrium is determinate in the baseline model if and only if $\phi_{\pi}+(1-\beta) \phi_{x} / \xi>1$, as shown by Woodford (2003).
} 
the policy specification by itself. The last evaluation criterion we consider, therefore, focuses more narrowly on the extent to which the systematic component of the policy rule accounts for the observed movements in the FFR, in the spirit of the $R^{2}$ in a regression.

Unfortunately, we are not aware of any formal approach to evaluating the fit of an individual equation in a DSGE model estimated with full-information methods. As an impressionistic alternative, the third row of Table 2 reports the standard deviation of the smoothed sequence of monetary policy shocks in each specification, denoted by $\operatorname{Std}\left(\varepsilon_{t \mid T}^{i}\right)$. This statistic measures the observed variation in the FFR left unexplained by the feedback component of the policy rule. It is the "sample analog" of the posterior estimate of the standard deviation of the monetary policy shock, $\sigma_{i}$, and is usually very close to the median of its posterior.

This standard deviation is 29 basis points for the $\mathrm{W}$ rule and 30 basis points for the $\mathrm{T}$ rule, a minor difference. However, the difference is larger (25 basis points for the $\mathrm{W}$ rule compared to 32 for the T rule) if we drop from the sample the recent recession, in which the nominal interest rate has fallen to its zero lower bound. This evidence suggests that in "normal" times the W rule accounts more closely for the systematic behavior of interest rates than the $\mathrm{T}$ rule. This advantage diminishes when a deep downturn drives the efficient interest rate well below the zero lower bound, as it did in the Great Recession.

\subsection{Wicksell and Taylor}

As pointed out in Section 2.1, our simple baseline model implies that an actual real rate that always matches its efficient counterpart ultimately closes the output gap, and vice versa. Therefore, these two approaches to stabilizing the real economy - closing the output or the interest rate gap - might be useful complements. To explore this possibility, we estimated a model with a combined W\&T rule of the form

$$
i_{t}=\rho i_{t-1}+(1-\rho)\left[r_{t}^{e}+\phi_{\pi} \pi_{t}+\phi_{x} x_{t}^{e}\right]+\varepsilon_{t}^{i} .
$$

This specification yields a modest improvement in fit over the baseline $\mathrm{W}$ rule of $4 \mathrm{KR}$ points, as shown in the first panel of Table 3. This improvement represents positive evidence that both the efficient real rate and the output gap contain useful information for policymakers on the state of the real economy. However, the much larger improvement in fit obtained by substituting $x_{t}^{e}$ with $r_{t}^{e}(21.4 \mathrm{KR}$ points moving from the $\mathrm{T}$ rule to the $\mathrm{W}$ rule), as compared to adding $x_{t}^{e}$ to $r_{t}^{e}$ (4 KR points moving from the $\mathrm{W}$ rule to the $\mathrm{W} \& \mathrm{~T}$ rule), suggests that the latter is by far the most useful real indicator between the two. In fact, the performance of the $\mathrm{W} \& \mathrm{~T}$ rule is inferior to that of the $\mathrm{W}$ rule in several of the alternative specifications considered in the robustness exercises, further strengthening the conclusion.

\section{[Locate Table 3 about here.]}

\subsection{Estimates of the Efficient Real Rate and of the Output Gap}

The evidence presented so far points to the efficient real rate as a crucial indicator for monetary policy. Figure 1 illustrates its estimated behavior over time. It plots smoothed posterior estimates of $r_{t}^{e}$ under the $\mathrm{W}, \mathrm{T}$ and W\&T models, along with the effective FFR. This picture drives home three important points.

[Locate Figure 1 about here.]

First, the estimated efficient real interest rate is a good business cycle indicator, rising during booms and dropping sharply in recessions. In fact, the efficient real interest rate conveys early signals of the upcoming slowdown in all three recessions in our sample, dropping sharply a few quarters before the recession starts, ahead of the turning point in the FFR. Second, the inferred movements in $r_{t}^{e}$ mirror quite closely those in the FFR, which helps explain the empirical success of $\mathrm{W}$ rules.

The co-movement between the FFR and the estimates of $r_{t}^{e}$ may raise the concern that the observations on the nominal interest rate "explain" the estimates of $r_{t}^{e}$, and not vice versa. However, this is not the case, which is the third message of the figure. In fact, the estimated time path of $r_{t}^{e}$ in the two models whose policy rules include it ( $\mathrm{W}$ and $\mathrm{W} \& \mathrm{~T}$ ) is very close to that under the $\mathrm{T}$ specification, in which $r_{t}^{e}$ does not affect interest rate setting. The main difference among the estimates is that the posterior distribution is tighter 
when $r_{t}^{e}$ enters the interest rate rule, as in the bands for the $\mathrm{W} \& \mathrm{~T}$ specification shown in the figure. This enhanced precision of the estimates suggests that the nominal interest rate does carry useful information on $r_{t}^{e}$, as should be expected, but that this information does not distort the inference on its median time-path.

Some intuition for the consistency of the estimates of $r_{t}^{e}$ across models can be gleaned from the expression for the efficient real interest rate presented in section 2 , which we report here for convenience

$$
r_{t}^{e}=E_{t} \gamma_{t+1}+E_{t} \delta_{t+1}-\omega E_{t} \Delta y_{t+1}^{e} .
$$

If efficient output growth were not expected to deviate from the balanced growth path (i.e. $E_{t} \Delta y_{t+1}^{e}=0$ ), the efficient real interest rate would be the sum of the forecastable movements in the growth rate of productivity $\gamma_{t}$ and in the intertemporal taste shock $\delta_{t}$. In the estimated models, $E_{t} \Delta y_{t+1}^{e}$ is indeed close to zero and the forecastable movements in $\gamma_{t}$ are small. The taste shock $\delta_{t}$, on the contrary, is large and persistent, so that its movements tend to be the main driving force of $r_{t}^{e}$. These movements are pinned down quite precisely by the estimation procedure, making the inference on the evolution of the efficient real rate remarkably consistent across models. In fact, this consistency extends well beyond the three specifications depicted in Figure 1 to virtually all the models considered in the robustness exercises, as illustrated in the online appendix.

We conclude this section by looking at the estimated output gap. This exercise is an important reality check on the baseline results, since one might wonder if the baseline $\mathrm{T}$ rule does not fit because it forces the interest rate to respond to an unreasonable gap measure. Figure 2 shows that this is not the case. In fact, the efficient output gap obtained under the T rule captures well the ups and downs of the business cycle, and conforms to standard views on the evolution of economic slack over the sample. Unlike with the estimates of $r_{t}^{e}$ reported in Figure 1, though, inference on the output gap is sensitive to the monetary policy specification. Under the $\mathrm{W}$ and $\mathrm{W} \& \mathrm{~T}$ rule, the output gap is less clearly cyclical than in the T specification, which makes it a less reliable indicator of real activity than the efficient real rate. This conclusion is further supported by the robustness analysis conducted in the next section, which shows that the superiority of the W rule survives many alternative approaches to measuring the output gap included in the T rule.

$$
\text { [Locate Figure } 2 \text { about here.] }
$$

\section{Robustness}

The comparison between the baseline $\mathrm{W}$ and $\mathrm{T}$ rules conducted so far suggests that the efficient interest rate captures the real economic developments to which the Federal Reserve has responded over the past twenty five years better than the efficient output gap. This section demonstrates that this result does not depend on the arbitrary choice of the baseline policy specifications. Regardless of how we measure the output gap, or of how we choose the other arguments of the policy function, W rules always fit the data better than comparable $\mathrm{T}$ rules. Moreover, this result remains true within a medium-scale DSGE model, along the lines of Christiano et al. (2005) and Smets and Wouters (2007).

\subsection{Output Gap}

The measure of the output gap included in the baseline $\mathrm{T}$ rule is the deviation of real GDP from its efficient level. This choice is fairly common in DSGE work (e.g. Smets and Wouters, 2007), but it is not without controversy in the broader macroeconomic literature, since efficient output can only be computed within a fully specified model. In fact, Taylor rules became so successful partly because they could be estimated without taking such a specific stance on how to measure economic slack, nor on the rest of the model.

To bridge the gap between our general equilibrium framework and the empirical work based on single equation methods, we examined several statistical approaches to the construction of smooth versions of potential output. In this section, we focus on one such approach, the Hodrick and Prescott (HP) filter, given its popularity in applied macroeconomics. The online appendix includes a discussion of our general approach to filtering within DSGE models, as well as results for several other filters we experimented with.

To make the HP filter operational within the DSGE framework, we adapt the methodology proposed by Christiano and Fitzgerald (2003) for the approximation of ideal band pass filters. These authors use 
forecasts and backcasts from an auxiliary time-series model - in their case a simple unit root process - to extend the available vector of observations into the infinite past and future. They then apply the ideal filter to this extended sample. In our implementation of their idea, the auxiliary model that generates the past and future dummy observations is the linearized DSGE itself.

This approach is particularly convenient because it produces a very parsimonious recursive expression for what we call the DSGE-HP gap $x_{t}^{H P}$

$$
\left[1+\lambda(1-L)^{2}(1-F)^{2}\right] x_{t}^{H P}=\lambda(1-L)^{2}(1-F)^{2} y_{t},
$$

where the operators $L$ and $F$ are defined by $L y_{t}=y_{t-1}$ and $F y_{t}=E_{t} y_{t+1}$, and the smoothing parameter $\lambda$ is set at the typical quarterly value of 1600 . This expression can thus be added to the system of rational expectations equations that defines the equilibrium of the model without dramatically augmenting the dimension of its state vector. ${ }^{9}$

When we estimate the model with a $\mathrm{T}$ rule in which $x_{t}^{H P}$ replaces the efficient output gap, the fit improves significantly compared to the baseline $\mathrm{T}$ specification (about $15 \mathrm{KR}$ points). However, it remains below that of the baseline $\mathrm{W}$ rule by close to 6 points, as shown at the bottom of panel I in Table 3 . This difference in fit between the $\mathrm{W}$ rule and the $\mathrm{T}$ rule with the HP output gap is fairly small in the baseline specification. However, in the next section we show that the difference becomes much larger (20 KR points) in the specifications with a time-varying inflation target, which further improves the fit of the model. Overall, these results confirm that the superior empirical performance of $\mathrm{W}$ over $\mathrm{T}$ rules is not sensitive to the measurement of the output gap.

To further substantiate this conclusion, the online appendix reports the fit of several alternative models in which the output gap in the $\mathrm{T}$ rule is measured with a variety of other filters. None of these alternative measures of the output gap helps the model fit better than the DSGE-HP gap described above. As an example, panel II of Table 3 considers the simplest among these alternative filters: the quarterly growth rate of output, which is a fairly common choice in estimated DSGEs. The performance of this $\mathrm{T}$ rule is in line with that of the baseline $\mathrm{T}$ specification, and hence it is substantially worse than that of the baseline $\mathrm{W}$ rule.

\subsection{Time-Varying Inflation Target}

In this section, we modify the baseline policy specification by introducing a time-varying inflation target (TVIT). This is a common feature in the recent empirical DSGE literature, which helps capture the lowfrequency movements in inflation and the nominal interest rate that are evident even in our relatively short sample (Ireland, 2007; Del Negro and Eusepi, 2011). This addition creates a new class of feedback rules, whose $\mathrm{W} \& \mathrm{~T}$ version is

$$
i_{t}=\rho i_{t-1}+(1-\rho)\left[r_{t}^{e}+\pi_{t}^{*}+\phi_{\pi}\left(\pi_{t}-\pi_{t}^{*}\right)+\phi_{x} x_{t}\right]+\varepsilon_{t}^{i}
$$

where $\pi_{t}^{*}$ is an exogenous $\mathrm{AR}(1)$ process representing persistent deviations of the inflation target from its long-run value $\pi^{*} .{ }^{10}$ The corresponding $\mathrm{W}$ rule has $\phi_{x}=0$, while the T rule does not include $r_{t}^{e}$.

The inclusion of a TVIT significantly improves the fit of the W model, as shown in panel II of Table 3. Its KR ratio with respect to the baseline $\mathrm{W}$ specification is around 24 points, very strong evidence in favor of the inclusion of this element in the policy rule. However, the TVIT does not have an equally positive effect on the performance of the other specifications. As a result, the gap between the $\mathrm{W}$ rule and its competitors is even larger in this panel than in the previous one. Among these competitors, the T rule with the HP output gap continues to outperform the one with $x_{t}^{e}$, but it is $20 \mathrm{KR}$ points below the $\mathrm{W}$ rule. Moreover, the $\mathrm{W} \& \mathrm{~T}$ rule does not improve over the $\mathrm{W}$ rule, unlike in the baseline case.

\footnotetext{
${ }^{9}$ The time series for the output gap obtained through this procedure (DSGE-HP) is very similar to that produced by the standard finite sample approximation of the HP filter applied to the GDP data. This result supports our use of the DSGE-HP filter as an effective detrending tool, which produces a measure of economic slack similar to those often used in single-equation estimates of the Taylor rule.

${ }^{10}$ The autocorrelation coefficient of $\pi_{t}^{*}$ has a Beta prior tightly distributed around a mean of 0.95 .
} 
These results suggest that the efficient real rate and a smoothly evolving inflation target enhance the empirical performance of the model through fairly independent channels. The former helps improve the business cycle properties of the model, while the latter helps capture the low frequency component of inflation, making them complementary features in policy specifications with good empirical properties.

\subsection{A Medium-Scale DSGE Model}

We conclude our investigation of interest rate rules by extending the comparison of $\mathrm{W}$ and $\mathrm{T}$ rules to a medium-scale DSGE model, along the lines of Christiano et al. (2005) and Smets and Wouters (2007). The exact specification we adopt for the behavior of the private sector behavior follows Justiniano et al. (2010) (henceforth, JPT), to which we refer the reader for further details. To make the exercise more directly comparable to that conducted in the baseline model, we estimate the JPT model on the same set of observables - GDP growth, inflation and the FFR - and on the same sample.

Panels III and IV of Table 3 report the results, which are even more strongly in favor of the $\mathrm{W}$ rule. First, the improvement in fit of the $\mathrm{W}$ over the $\mathrm{T}$ rule is $51 \mathrm{KR}$ points, the largest among all the models we considered. Second, adding the output gap to the W rule to form the W\&T specification brings a further improvement, albeit small. Also in this model, therefore, the efficient real rate is the most effective measure of real economic developments from the perspective of monetary policy. Third, the introduction of a TVIT improves the model's fit, but it leaves intact the superiority of the W rule, which now amounts to $39 \mathrm{KR}$ points over the $\mathrm{T}$ rule.

To put these differences in fit in perspective, Cúrdia et al. (2014) report that the inclusion of stochastic volatility within a DSGE structure very similar to that of JPT improves their model's fit by about $68 \mathrm{KR}$ points. This consideration suggests that choosing an appropriate policy specification can yield comparable gains in fit as correctly specifying its driving processes, which are widely regarded as crucial to the empirical success of these models.

Finally, Figure 3 compares the estimated time series of $r_{t}^{e}$ in the baseline and JPT models under the W\&T policy rule. We chose this specification because it is the best fitting one, but very similar results hold for the baseline $\mathrm{W}$ rule, as well as for the $\mathrm{W} \& \mathrm{~T}$ and $\mathrm{W}$ rules with a time varying inflation target. The estimated efficient rate retains the cyclical properties stressed in section 4.2 also in the JPT model, although its fluctuations are more muted than in the baseline. This reduction in estimated volatility is probably due to the richer set of frictions (and shocks) included by JPT, which account for some of the movement in the data through endogenous propagation and amplification channels omitted from the baseline model. These channels reduce the role of the intertemporal shock $\delta_{t}$, which is the key driver of the efficient rate in that model. We conclude that the estimates of the efficient real rate are at least qualitatively robust to major changes in the model, as well as to changes in the policy specification, as also illustrated in Figure 1.

[Locate Figure 3 about here.]

\section{Conclusions}

Ever since Taylor (1993), central banks are universally described as setting short-term interest rates in response to inflation and some measure of the output gap. This paper proposes an alternative view of the real factors driving interest rate decisions. Rules in which the policy instrument tracks the efficient interest rate as the main measure of real economic developments fit the data better than equivalent specifications that respond to the output gap. We refer to this class of rules as W rules, from Wicksell (1898), whose neutral interest rate is a precursor of the efficient rate of return considered here.

Since this efficient rate is a counterfactual object - the rate of return that would prevail under perfect competition - its measurement requires a structural model. Therefore, we conducted our empirical investigation within a New Keynesian DSGE framework, using Bayesian methods to estimate its parameters and to compare the fit of many alternative specifications. Across all these specifications, which differ for the details of the policy rule, as well as for the assumptions on the behavior of the private sector, $\mathrm{W}$ rules proved consistently superior to equivalent Taylor rules.

Notwithstanding its robustness, this result is subject to two caveats. First, model specification matters, since our criterion of fit depends on the interaction of the policy rule with the rest of the model. More work 
across different models would therefore be desirable, although we already address this issue by illustrating the robustness of the results in two popular DSGE specifications. Second, model comparison through marginal data densities and Bayes factors applied to DSGE models is subject to some pitfalls, highlighted for example by Del Negro and Schorfheide (2011). However, the large improvements in fit uncovered when moving from $\mathrm{W}$ to $\mathrm{T}$ rules suggest that the specification of the policy reaction function does make a significant difference.

Going forward, we expect to devote some of our research to further scrutinize the role of the efficient real interest rate as a useful policy indicator, from both a positive and a normative perspective. In particular, we would like to explore more realistic assumptions on the information available to policy makers when taking their decisions, focusing on the fact that the efficient real interest rate is not observable in practice, unlike in our model. These assumptions would also give rise to an interesting tradeoff between the usefulness of $r_{t}^{e}$ as a business cycle indicator, highlighted in this paper, and the (in)ability of policymakers to observe it with precision, especially in real time. 


\section{References}

Amato, J., 2005. The role of the natural rate of interest in monetary policy. BIS Working Paper No. 171.

An, S., Schorfheide, F., 2007. Bayesian analysis of DSGE models. Econometric Reviews 26, $113-172$.

Barsky, R., Justiniano, A., Melosi, L., 2014. The natural rate of interest and its usefulness for monetary policy. American Economic Review 104, 37-43.

Bils, M., Klenow, P., 2004. Some evidence on the importance of sticky prices. Journal of Political Economy $112,947-985$.

Christiano, L., Eichenbaum, M., Evans, C., 2005. Nominal rigidities and the dynamic effects of a shock to monetary policy. Journal of Political Economy 113, 1-45.

Christiano, L., Fitzgerald, T., 2003. The band pass filter. International Economic Review 44, 435-465.

Clarida, R., Galí, J., Gertler, M., 2000. Monetary policy rules and macroeconomic stability: Evidence and some theory. Quarterly Journal of Economics 115, 147-180.

Coibion, O., Gorodnichenko, Y., 2011. Monetary policy, trend inflation, and the Great Moderation: An alternative interpretation. American Economic Review 101, 341-370.

Cúrdia, V., Del Negro, M., Greenwald, D., 2014. Rare large shocks in the U.S. business cycle. Journal of Applied Econometrics, forthcoming.

Del Negro, M., Eusepi, S., 2011. Fitting observed inflation expectations. Journal of Economic Dynamics and Control 35 (12), 2105-2131.

Del Negro, M., Schorfheide, F., 2011. Bayesian macroeconometrics. In: Geweke, J., Koop, G., Van Dijk, H. (Eds.), Handbook of Bayesian Econometrics. Oxford University Press, pp. 293-289.

Galí, J., Gertler, M., 2007. Macroeconomic modeling for monetary policy evaluation. Journal of Economic Perspectives 21, 25-46.

Geweke, J., 1999. Using simulation methods for Bayesian econometric models: Inference, development, and communication. Econometric Reviews 18, 1-126.

Giannoni, M., 2014. Optimal interest rate rules and inflation stabilization versus price-level stabilization. Journal of Economic Dynamics and Control 41, 110-129.

Ireland, P., 2007. Changes in the Federal Reserve's inflation target: Causes and consequences. Journal of Money, Credit, and Banking 39, 1851-1882.

Justiniano, A., Primiceri, G., Tambalotti, A., 2010. Investment shocks and business cycles. Jounral of Monetary Economics 57, 132-145.

Justiniano, A., Primiceri, G., Tambalotti, A., 2013. Is there a trade-off between inflation and output stabilization? American Economic Journal: Macroeconomics 5, 1-31.

Kass, R., Raftery, A., 1995. Bayes factors. Journal of the American Statistical Association 90, 773-795.

King, R., Wolman, A., 1999. What should the monetary authority do when prices are sticky? In: Taylor, J. (Ed.), Monetary Policy Rules. University of Chicago Press, pp. 349-404.

McCallum, B., Nelson, E., 2011. Money and inflation: Some critical issues. In: Friedman, B. M., Woodford, M. (Eds.), Handbook of Monetary Economics. Vol. 3A. Elsevier/North-Holland, pp. 97-153.

Neiss, K., Nelson, E., 2003. The real-interest-rate gap as an inflation indicator. Macroeconomic Dynamics 7 , $239-262$. 
Sbordone, A., 2002. Prices and unit labor costs: A new test of price stickiness. Journal of Monetary Economics 49, 265-292.

Schorfheide, F., 2008. DSGE model-based estimation of the New Keynesian Phillips curve. Federal Reserve Bank of Richmond Economic Quarterly 94, 397-433.

Smets, F., Wouters, R., 2007. Shocks and frictions in U.S. business cycles: A Bayesian DSGE approach. American Economic Review 97, 586-606.

Taylor, J. B., 1993. Discretion versus policy rules in practice. Carnegie-Rochester Conference Series on Public Policy 39, 195-214.

Trehan, B., Wu, T., 2007. Time-varying equilibrium real rates and monetary policy analysis. Journal of Economic Dynamics and Control 31, 1584-1609.

Wicksell, K., 1898. Interest and Prices (English translation by R.F. Kahn, 1936). Macmillan, London.

Woodford, M., 2003. Interest and Prices: Foundations of a Theory of Monetary Policy. Princeton University Press. 


\begin{tabular}{llccc}
\hline Parameter & Distribution & $5 \%$ & Median & $95 \%$ \\
\hline$\omega$ & $G(1,0.2)$ & 0.70 & 0.99 & 1.35 \\
$\xi$ & $G(0.1,0.05)$ & 0.03 & 0.09 & 0.19 \\
$\eta$ & $B(0.6,0.2)$ & 0.25 & 0.61 & 0.90 \\
$\zeta$ & $B(0.6,0.2)$ & 0.25 & 0.61 & 0.90 \\
$\rho$ & $B(0.7,0.15)$ & 0.43 & 0.72 & 0.92 \\
$\phi_{\pi}$ & $N(1.5,0.25)$ & 1.09 & 1.50 & 1.91 \\
$4 \phi_{x}$ & $N(0.5,0.2)$ & 0.17 & 0.50 & 0.83 \\
$400 \pi^{*}$ & $N(2,1)$ & 0.36 & 2.00 & 3.64 \\
$400 r$ & $N(2,1)$ & 0.36 & 2.00 & 3.64 \\
$400 \gamma$ & $N(3,0.35)$ & 2.42 & 3.00 & 3.58 \\
$\rho_{\delta}$ & $B(0.5,0.2)$ & 0.17 & 0.50 & 0.83 \\
$\rho_{\gamma}$ & $B(0.5,0.2)$ & 0.17 & 0.50 & 0.83 \\
$\rho_{u}$ & $B(0.5,0.2)$ & 0.17 & 0.50 & 0.83 \\
$\sigma_{\delta}$ & $I G 1(0.5,2)$ & 0.17 & 0.34 & 1.24 \\
$\sigma_{\gamma}$ & $I G 1(0.5,2)$ & 0.17 & 0.34 & 1.24 \\
$\sigma_{u}$ & $I G 1(0.5,2)$ & 0.17 & 0.34 & 1.24 \\
$\sigma_{i}$ & $I G 1(0.5,2)$ & 0.17 & 0.34 & 1.24 \\
\hline
\end{tabular}

Table 1: Prior distributions for the parameters in the baseline model. G stands for Gamma, B stands for Beta, N stands for Normal and IG1 stands for Inverse Gamma 1, with mean and standard deviation in parenthesis 


\begin{tabular}{lcccccc}
\hline Summary statistics & \multicolumn{3}{c}{ T rule } & \multicolumn{3}{c}{ W rule } \\
\hline ML & \multicolumn{3}{c}{-371.45} & & \multicolumn{3}{c}{-360.74} \\
KR & \multicolumn{3}{c}{-21.6} & & & - \\
Std $\left(\varepsilon_{t \mid T}^{i}\right)$ & \multicolumn{3}{c}{0.30} & & \multicolumn{3}{c}{0.29} & \\
\hline Parameter & $5 \%$ & Median & $95 \%$ & $5 \%$ & Median & $95 \%$ \\
\hline$\omega$ & 0.70 & 0.99 & 1.35 & 0.66 & 0.94 & 1.29 \\
$100 \xi$ & 0.08 & 0.21 & 0.50 & 1.49 & 3.03 & 5.54 \\
$\eta$ & 0.49 & 0.62 & 0.73 & 0.35 & 0.47 & 0.58 \\
$\zeta$ & 0.10 & 0.48 & 0.81 & 0.06 & 0.18 & 0.39 \\
$\rho$ & 0.65 & 0.75 & 0.82 & 0.78 & 0.81 & 0.84 \\
$\phi_{\pi}$ & 0.70 & 1.14 & 1.62 & 1.24 & 1.47 & 1.73 \\
$4 \phi_{x}$ & 0.95 & 1.19 & 1.44 & - & - & - \\
$400 \pi^{*}$ & 1.89 & 2.38 & 2.85 & 1.84 & 2.39 & 2.92 \\
$400 r$ & 0.89 & 1.88 & 2.86 & 1.70 & 2.34 & 2.98 \\
$400 \gamma$ & 2.48 & 2.93 & 3.39 & 2.40 & 2.95 & 3.50 \\
$\rho_{\delta}$ & 0.85 & 0.91 & 0.95 & 0.28 & 0.63 & 0.85 \\
$\rho_{\gamma}$ & 0.21 & 0.55 & 0.89 & 0.93 & 0.97 & 0.99 \\
$\rho_{u}$ & 0.06 & 0.37 & 0.73 & 0.81 & 0.89 & 0.93 \\
$\sigma_{\delta}$ & 0.81 & 1.29 & 2.05 & 0.21 & 0.78 & 2.16 \\
$\sigma_{\gamma}$ & 0.65 & 1.88 & 3.69 & 0.85 & 1.07 & 1.39 \\
$\sigma_{u}$ & 0.18 & 0.41 & 0.60 & 0.20 & 0.29 & 0.44 \\
$\sigma_{i}$ & 0.25 & 0.33 & 0.42 & 0.23 & 0.31 & 0.38 \\
\hline
\end{tabular}

Table 2: Estimation results for the baseline $\mathrm{T}$ and $\mathrm{W}$ specifications. ML is the marginal likelihood. KR is the KR ratio with respect to the W model. $\operatorname{Std}\left(\varepsilon_{t \mid T}^{i}\right)$ is the standard deviation of the smoothed sequence of monetary policy residuals. $5 \%$, Median, and $95 \%$ are the 5th percentile, the median, and the 95th percentile of the posterior distribution for each parameter from the MCMC draws. The posterior of the slope of the Phillips curve is quoted as $100 \xi$ because it would otherwise be too small in the $\mathrm{T}$ specification. 


\begin{tabular}{llrr}
\hline Name & Policy Rule $\left(i_{t}^{*}\right)$ & KR & ML \\
\hline Panel I: Baseline E & Output Gaps & & \\
W & $r_{t}^{e}+\phi_{\pi} \pi_{t}$ & -360.7 \\
T & $\phi_{\pi} \pi_{t}+\phi_{x} x_{t}^{e}$ & -21.4 & \\
W\&T & $r_{t}^{e}+\phi_{\pi} \pi_{t}+\phi_{x} x_{t}^{e}$ & 4.0 & \\
T with HP Gap & $\phi_{\pi} \pi_{t}+\phi_{x} x_{t}^{H}$ & -5.6 & \\
T with Growth & $\phi_{\pi} \pi_{t}+\phi_{\Delta y}\left(y_{t}-y_{t-1}\right)$ & -21.2 & \\
\hline Panel II: Time Varying Inflation Target $($ TVIT & & \\
W & $r_{t}^{e}+\pi_{t}^{*}+\phi_{\pi}\left(\pi_{t}-\pi_{t}^{*}\right)$ & & -348.9 \\
T & $\pi_{t}^{*}+\phi_{\pi}\left(\pi_{t}-\pi_{t}^{*}\right)+\phi_{x} x_{t}^{e}$ & -32.0 & \\
W\&T & $r_{t}^{e}+\pi_{t}^{*}+\phi_{\pi}\left(\pi_{t}-\pi_{t}^{*}\right)+\phi_{x} x_{t}^{e}$ & 0.1 & \\
T with HP Gap & $\pi_{t}^{*}+\phi_{\pi}\left(\pi_{t}-\pi_{t}^{*}\right)+\phi_{x} x_{t}^{H P}$ & -20.0 & \\
T with Growth & $\pi_{t}^{*}+\phi_{\pi}\left(\pi_{t}-\pi_{t}^{*}\right)+\phi_{\Delta y}\left(y_{t}-y_{t-1}\right)$ & -36.3 & \\
\hline Panel III: JPT Model & & \\
W & $r_{t}^{e}+\phi_{\pi} \pi_{t}$ & -19.1 \\
T & $\phi_{\pi} \pi_{t}+\phi_{x} x_{t}^{e}$ & & \\
W\&T & $r_{t}^{e}+\phi_{\pi} \pi_{t}+\phi_{x} x_{t}^{e}$ & & \\
\hline Panel IV: JPT Model with TVIT & & -12.3 \\
W & $r_{t}^{e}+\pi_{t}^{*}+\phi_{\pi}\left(\pi_{t}-\pi_{t}^{*}\right)$ & -38.9 & \\
T & $\pi_{t}^{*}+\phi_{\pi}\left(\pi_{t}-\pi_{t}^{*}\right)+\phi_{x} x_{t}^{e}$ & \\
W\&T & $r_{t}^{e}+\pi_{t}^{*}+\phi_{\pi}\left(\pi_{t}-\pi_{t}^{*}\right)+\phi_{x} x_{t}^{e}$ & 1.3 & \\
\hline
\end{tabular}

Table 3: Comparison of policy rules. Each panel shows the log-marginal likelihood (ML) for the relevant W rule, and the $\mathrm{KR}$ ratio for the other rules relative to the $\mathrm{W}$ rule. The second column contains the systematic component of the rule under consideration in the absence of interest rate smoothing $\left(i_{t}^{*}\right)$, defined such that $i_{t}=\rho i_{t-1}+(1-\rho) i_{t}^{*}+\varepsilon_{t}^{i}$. 


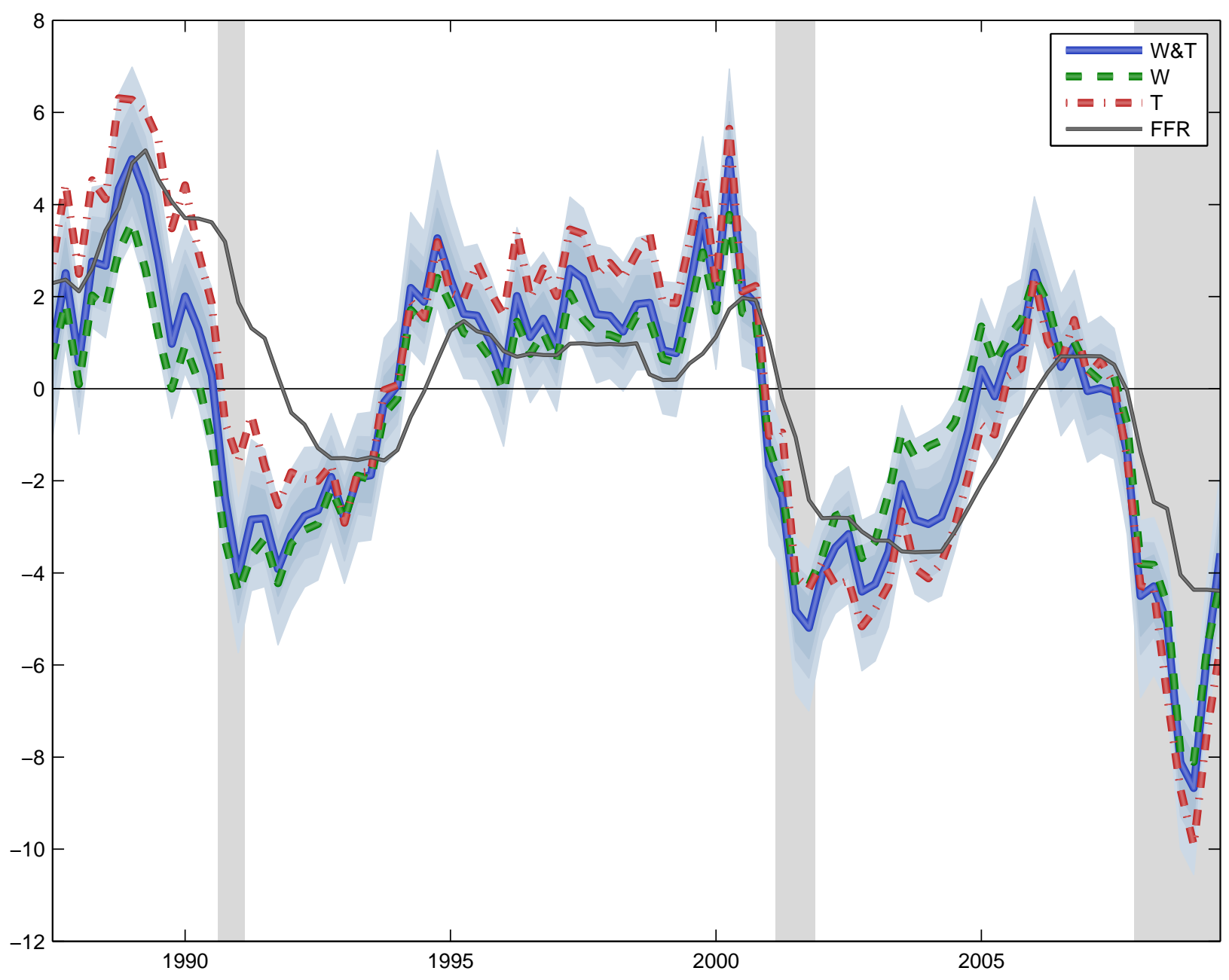

Figure 1: Effective Federal Funds rate (FFR) and smoothed estimates of the efficient real interest rate across three policy specifications (W\&T, W and T) in the baseline model. The rates are demeaned and expressed in annualized percentage points. The thicker lines are the posterior medians of the efficient real rate in the baseline model estimated with the W\&T, W, and $\mathrm{T}$ policy rules. Different shades of light blue represent the 50, 70 and 90 percent posterior probability bands for the W\&T specification. Vertical grey areas mark NBER recessions. 


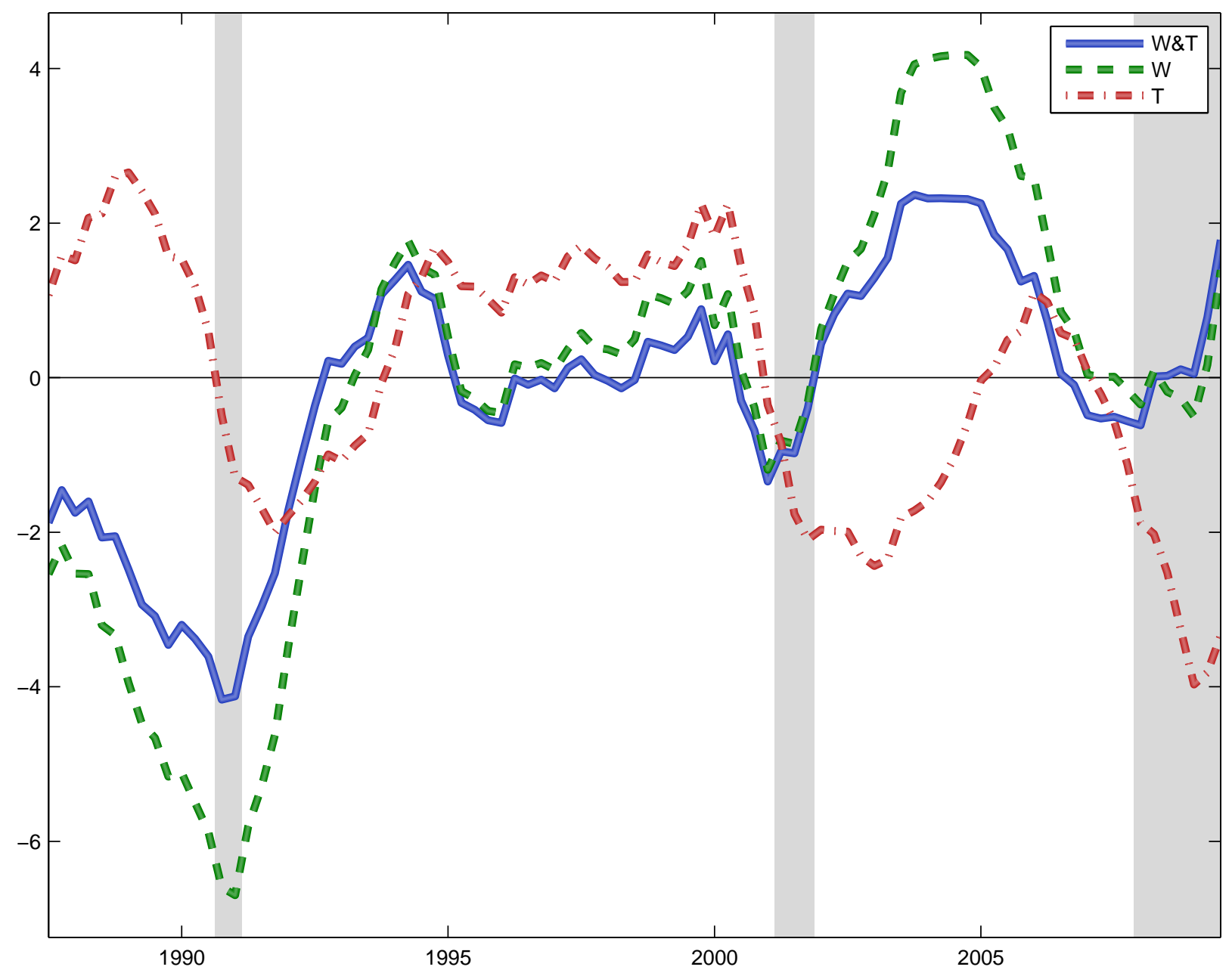

Figure 2: Smoothed posterior median estimates of the efficient output gap across three policy specifications (W\&T, W and T) in the baseline model. Vertical grey areas mark NBER recessions. 


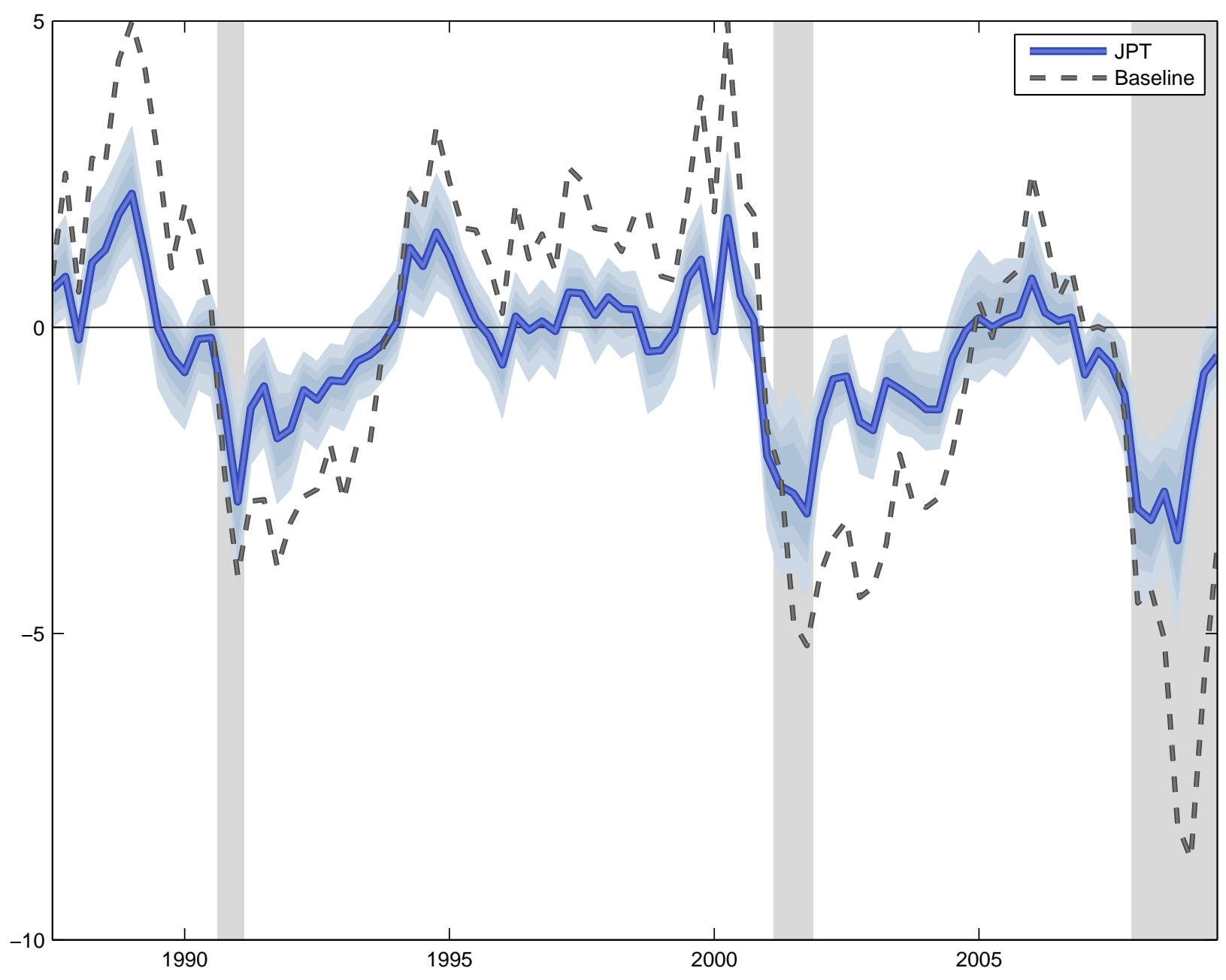

Figure 3: Smoothed posterior median estimates of the efficient real interest rate in the baseline and JPT models, both estimated with the W\&T rule. The rates are demeaned and expressed in annualized percentage points. Different shades of light blue represent the 50,70 and 90 percent posterior probability bands for the W\&T specification. Vertical grey areas mark NBER recessions. 